\title{
A distinção foco/tópico em tzotzil, jakaltek, tembé, xavante, português brasileiro e português europeu ${ }^{1}$
}

\author{
The focus and topic distinction in Tzotzil, Jakaltek, \\ Tembé, Xavante, Brazilian and European Portuguese
}

\author{
Flaviane Romani Fernandes Svartman \\ Unicamp
}

\begin{abstract}
This paper presents similarities and differences between Tzotzil, Jakaltek, Tembé, Xavante, Brazilian Portuguese (BP) and European Portuguese (EP) regarding the focus and topic distinction. Based on similarities and differences between these languages, we propose a linguistic grouping of them. We observe that beyond the distinction between them in relation to strategies of the focus and topic distinction, it is also possible to distinguish close languages, as EP and $\mathrm{BP}$, considering the focus phenomenon. Whereas EP can distinguish different focus types by different strategies, BP signs focus essentially by the assignment of the main prominence of the sentence.
\end{abstract}

Keywords

Focus; Topic; Linguistics Typology.

\section{Resumo}

Neste trabalho são apresentadas as semelhanças e diferenças quanto às estratégias utilizadas por tzotzil, jakaltek, tembé, xavante, português brasileiro (PB) e português europeu (PE) na marcação e distinção de 
foco e tópico. Com base nas semelhanças e diferenças entre essas línguas, propusemos um agrupamento lingüístico para elas. Constatamos que, além da possibilidade de distinção entre elas através das estratégias utilizadas na marcação e distinção entre foco e tópico, é possível distinguir mesmo línguas muito próximas, como $\mathrm{PB}$ e PE, quanto ao fenômeno da focalização. Enquanto PE pode distinguir diferentes tipos de foco através do uso de diferentes estratégias, PB marca foco em geral essencialmente pelo assinalamento de proeminência fonológica principal da sentença.

\section{Palavras-chave}

Foco; Tópico; Tipologia lingüística. 


\section{Introdução}

$\mathrm{E}$

ste trabalho, de cunho tipológico, consiste em um estudo comparativo das

diferentes estratégias utilizadas por tzotzil, jakaltek, português brasileiro (doravante, PB) e português europeu (doravante, PE) na marcação e distinção de foco e tópico. Com base em trabalhos já realizados sobre foco e tópico nas referidas línguas, nosso objetivo é apresentar, de maneira introdutória, uma descrição comparativa sobre os padrões de expressão das funções pragmáticas de tópico e foco.

Tzotzil e jakaltek são duas línguas indígenas da América Central e pertencem ao grupo das línguas Maya. Tembé e xavante são duas línguas indígenas brasileiras, sendo que a primeira pertence ao tronco Tupi e a segunda, ao tronco Macro-Jê. Por sua vez, PB e PE são duas variedades do português (língua indo-européia), respectivamente faladas no Brasil e em Portugal. Destacamos que, embora as línguas abordadas neste trabalho sejam de troncos lingüísticos diferentes, é possível compará-las na medida em que compartilham características das línguas naturais.

Primeiramente, apresentaremos as estratégias utilizadas pelas línguas mencionadas na marcação de tópico e foco e buscaremos identificar as diferenças e semelhanças entre as mesmas línguas quanto à marcação desses dois fenômenos lingüísticos.

Por fim, tentaremos estabelecer uma tipologização baseada nas diferenças e semelhanças quanto à marcação de foco e tópico em tzotzil, jakaltek, tembé, xavante, $\mathrm{PB}$ e PE.

O presente trabalho será apresentado em quatro seções:

(i) Na primeira seção, apresentaremos uma breve caracterização de foco e tópico;

(ii) Na segunda seção, apresentaremos as diferentes estratégias das quais as línguas podem se utilizar na marcação de foco e tópico e apresentaremos, levando em consideração a literatura lingüística relevante, as estratégias utilizadas por tzotzil, jakaltek, tembé, xavante, PB e PE na marcação desses fenômenos lingüísticos; 
(iii) Por sua vez, na terceira seção, tentaremos agrupar tipologicamente tzotzil, jakaltek, tembé, xavante, PB e PE segundo suas semelhanças e diferenças na marcação de foco e tópico;

(iv) Finalmente, na quarta e última seção, apresentaremos nossas considerações finais.

\section{Caracterização de foco e tópico}

\subsection{Caracterização do foco}

Na literatura sobre foco em línguas como o inglês, o conceito de foco pode apresentar três tipos de correlatos: um correlato fonológico, um correlato semântico e /ou pragmático e um correlato sintático. Os autores podem diferir quanto à escolha de um dos correlatos como caracterizador desse fenômeno lingüístico, porém, conforme Frota (2000), independentemente da escolha por caracterizar o foco pelo correlato semântico ou sintático, o foco sempre apresenta o correlato fonológico como elemento recorrente.

Segundo Frota (2000), a idéia de que a fonologia desempenha um papel decisivo na caracterização do fenômeno do foco tem uma longa tradição na literatura gerativa. Em Chomsky (1971), o foco é visto como um reflexo da fonologia uma vez que é determinado pelo "centro entoacional da estrutura superficial" (the intonational center of surface structure, CHOMSKY, 1971, p. 201). Este trabalho pioneiro apresenta o que podemos chamar de "visão fonológica" do foco (nos termos de REINHART, 1995, uma visão do foco em PF (Forma Fonológica - do inglês, Phonological Form)). Conforme Frota (2000), em trabalhos subseqüentes, em que o foco era tratado de um ponto de vista semântico/ pragmático ou sintático, as propriedades fonológicas não eram vistas como determinadoras do foco, mas eram tomadas como reflexo de um foco determinado independentemente.

O ponto de vista semântico/pragmático do foco, particularmente no domínio da entoação, inclui basicamente dois modos de tratamento: um tratamento baseado em acento (highlighting-based) e um tratamento baseado na estrutura (structure-based). ${ }^{2}$ No tratamento do foco baseado em acento, cf. Bolinger (1972) ou Schmerling (1976), o foco e a distribuição dos acentos tonais dependem de fatores semânticos e discursivos relativos a questões de informação e contexto de enunciado. Ao contrário, no tratamento baseado na estrutura (cf. LADD, 1980; GUSSENHOVEN, 1983; 1992), o foco é definido de acordo com 
a intenção do falante e com o contexto, e a distribuição de acentos tonais é determinada por fatores estruturais como a distinção argumento/predicado. Independentemente das diferenças entre essas duas abordagens, ambas contam com o acento tonal para marcar o foco.

A visão sintática sobre o foco foi primeiramente proposta por Jackendoff (1972). No trabalho de Jackendoff, o foco é um traço sintático relevante tanto para a interpretação (LF - Forma Lógica, do inglês Logical Form) quanto para a fonologia $(\mathrm{PF})$. Ainda que Jackendoff defina o foco essencialmente na sintaxe (sendo o elemento focalizado aquele que carrega o traço sintático $[+\mathrm{F}]$ ), este autor estabelece claramente que o acento é o critério para assinalar o foco e o traço de foco $[+\mathrm{F}]$ "contém uma característica marcada no contorno entoacional" para ser sintaticamente associado ao constituinte focalizado (JACKENDOFF, 1972, p. 234, 262). Isso significa que a abordagem sintática também depende de características fonológicas (proeminência e acento tonal), assim como a abordagem sintática de foco desenvolvida em trabalhos como o de Culicover \& Rochemont (1983) e Winkler (1997).

De acordo com Culicover \& Rochemont (1983), a identificação do foco depende de um acento marcado na estrutura superficial (SS - Superficial Structure) que é o input para PFe LF. Essa estrutura é derivada através da aplicação de uma regra de "assinalamento forte", que assinala o acento na estrutura superficial. Novamente, a explicação sintática depende da característica fonológica. Na proposta de Winkler (1997) há um assinalamento livre na estrutura profunda (DS - Deep Structure) de um traço de proeminência [P] que é o input para o assinalamento de um traço foco $[\mathrm{F}]$. [P] é interpretado por PF, enquanto $[\mathrm{F}]$ é interpretado por LF. Contrariamente à abordagem sintática anterior, o assinalamento de traço em estrutura profunda é motivado por considerações de estrutura de argumento. Similarmente às abordagens sintáticas anteriores, uma característica fonológica novamente é requerida.

Alguns trabalhos um pouco mais recentes desenvolvidos em uma abordagem sintática têm sido caracterizados por um retorno à abordagem do foco em PF de Chomsky (1971), no sentido de que é assumido explicitamente que o acento de sentença - que é marcado em PF - é o determinador do foco (cf. CINQUE, 1993; REINHART, 1995; ZUBIZARRETA, 1998). Entretanto, nesses trabalhos, é negado, ou explicitamente ou implicitamente, o papel da estrutura prosódica no assinalamento do acento principal de sentença ou do acento de foco. 
Nosso objetivo no presente trabalho não é abordar o foco de um ponto de vista fonológico ou semântico ou sintático, de maneira que um correlato caracterizador do foco seja "o determinador" do fenômeno do foco e seja responsável pelo desencadeamento dos demais correlatos. Buscaremos apenas identificar os correlatos morfológicos, sintáticos ou fonológicos, que muitas vezes podem estar co-relacionados, os quais possibilitam a marcação do elemento focalizado nas sentenças de tzotzil, jakaltek, tembé, xavante, PB e PE. Procuraremos também estabelecer semelhanças e diferenças entre essas línguas quanto às diferentes maneiras escolhidas por elas na marcação do foco.

Assumiremos aqui que um constituinte focalizado pode ser assim caracterizado:

(i) do ponto de vista fonológico, como o elemento que carrega a proeminência fonológica principal de sentença; ${ }^{3}$

(ii) do ponto de vista semântico/pragmático, como o elemento que carrega a informação nova no enunciado; e

(iii) do ponto de vista sintático, como o elemento que ocupa uma posição sintática correspondente ao local de culminância da proeminência fonológica principal do enunciado (no caso de línguas que marcam foco através de proeminência e por posição sintática),ou correspondente ao local de adjunção de uma marca morfológica identificadora de foco (caso de línguas que marcam foco morfologicamente e por posição sintática) ou ainda correspondente à posição específica que um elemento focalizado deve ocupar na estrutura sintática do enunciado (línguas que marcam foco apenas pela posição que os elementos ocupam na sentença).

No que concerne aos tipos de foco, destaca-se que as línguas podem apresentar diferentes tipos. Gussenhoven (2006) afirma que, em inglês, podemos encontrar: (1) foco de informação (foco de apresentação, na denominação de Gussenhoven), (2) foco de correção, (3) foco de contrapressuposição, (4) foco de definição, (5) foco de contingência, (6) foco de reativação e (7) foco de identificação. Os tipos de foco mais comumente encontrados nas línguas são, conforme a classificação do mesmo autor, foco de apresentação e foco corretivo.

O foco de apresentação (foco de informação) é utilizado quando o constituinte focalizado carrega informação nova no discurso e é parte da sentença que corresponde à resposta a uma pergunta: 
(1) O que Paulo comprou?
Paulo comprou um livro.

O foco corretivo, também chamado de contrastivo, é utilizado em situações de correção para negar uma pressuposição implícita ou explícita contida em um enunciado prévio:

(2) O Paulo comprou uma bola?

(Não) O Paulo comprou um livro.

Faz-se necessário acrescentar que, muitas vezes, o foco de apresentação (foco de informação) e o foco contrastivo são tratados como um só tipo de foco, "foco de escopo estreito", porém há línguas, como efik, por exemplo, que fazem uma clara distinção entre o foco corretivo e o foco de apresentação. Em efik, o elemento que expressa foco de correção requer uma partícula que indica foco corretivo (cf. de JONG, 1980; GUSSENHOVEN, 1983).

Acrescenta-se que, além dos tipos de foco apresentados por Gussenhoven (2006), as línguas também podem apresentar o "foco de escopo largo". Esse tipo de foco se refere a casos em que toda a sentença consiste em uma nova informação, i. é., contextos out-of-the-blue:

(3) O que aconteceu?

Eu dei um livro ao João.

No presente trabalho, trataremos da marcação de foco de escopo estreito, em seu sentido mais amplo (envolvendo foco de apresentação - isto é, foco de informação-e/ou contrastivo), em constituintes simples (constituintes compostos por uma única cabeça lexical) em sentenças de tzotzil, jakaltek, tembé, xavante, PB ePE. Portanto, foco dobrado/múltiplo ou lista de foco estão fora do escopo deste estudo.

\subsection{Caracterização do tópico}

Li \& Thompson (1976) propõem uma tipologia das línguas baseada na predominância nelas das relações de tópico-comentário ou de sujeito-predicado. Segundo essa tipologia, as línguas seriam divididas em quatro grupos:

(a) línguas com proeminência de sujeito, em que a estrutura das sentenças é mais bem descrita como de sujeito-predicado;

(b) línguas com proeminência de tópico, em que a estrutura das sentenças é mais bem descrita como de tópico-comentário; 
(c) línguas com proeminência de tópico e sujeito, em que há as duas construções diferentes;

(d) línguas sem proeminência de sujeito ou tópico, em que o sujeito e o tópico se mesclaram e não se distinguem mais os dois tipos.

Pontes (1987) cita como exemplos do primeiro tipo, entre outras, as línguas indo-européias; do segundo tipo, o chinês e o lahu; do terceiro tipo, o japonês; e, por sua vez, como exemplo do quarto tipo, a mesma autora cita o tagalog. Pontes (1987) ainda acrescenta que Li \& Thompson advertem, porém, que não é fácil estabelecer de que tipo uma língua é, uma vez que a gramática tradicional e mesmo a lingüística têm partido do pressuposto de que a construção sujeitopredicado é uma construção universal e, por isso, têm descrito as diferentes línguas sempre do mesmo modo.

Neste estudo não estabeleceremos uma tipologização para jakaltek, tzotzil, xavante, tembé, PB e PE quanto à predominância das relações tópico-comentário ou sujeito-predicado, apenas identificaremos a maneira como essas mesmas línguas marcam elementos topicalizados no discurso e como os diferenciam de elementos focalizados.

Para Chafe (1976), assim como para Li \& Thompson (1976), deve-se tomar como protótipo o tópico em línguas como o chinês, no qual as características do tópico podem ser contrapostas às que o sujeito costuma apresentar nas línguas em que este é proeminente. Segundo esses mesmos autores, o que caracteriza o tópico nas línguas como o chinês é o fato de esse elemento estabelecer um quadro de referência para o que vai ser dito a seguir.

Quanto às características apresentadas pelo tópico em chinês e em outras línguas de tópico, baseados em Li \& Thompson (1976), podemos elencar, entre outras, as seguintes características:

(i) O tópico é sempre definido, enquanto o sujeito pode ser indefinido;

(ii) $\mathrm{O}$ tópico não precisa ter relações selecionais com o verbo, a não ser nos casos em que o tópico é idêntico ao sujeito;

(iii) O verbo determina o sujeito, mas não o tópico;

(iv) O papel funcional do tópico é constante: ele é o centro da atenção e anuncia o tema do discurso;

(v) O tópico raramente apresenta concordância verbal, a não ser nos casos em que o tópico é o próprio sujeito do enunciado;

(vi) O tópico geralmente aparece na posição inicial da sentença. 
Essas características apresentadas para tópico são ilustradas pelo exemplo (5) de tópico em PB, extraído de Pontes (1987, p. 14):

(4) A. E a Rosa?

B. A Rosa eu falei com ela ontem.

No exemplo (4), o tópico "Rosa" é definido, o que pode ser constatado pela presença do artigo definido "a" antes desse elemento, não desencadeia concordância com o verbo, uma vez que o verbo concorda com o sujeito "eu" da sentença ("eu falei"), é o centro da atenção no discurso, aparece na posição inicial da sentença, não mantém relações selecionais com o verbo nem é determinado por ele, na medida em que a relação selecional se estabelece entre o verbo "falar" e seu sujeito "eu" e a seleção do tópico "Rosa" é independente do verbo (a seleção do tópico "Rosa" é independente tanto do verbo como do sujeito da sentença). Conforme Pontes (1987), todas essas características apontam para o fato de que o tópico é dependente do discurso, enquanto o sujeito é dependente da sentença.

A essas características apresentadas por Li \& Thompson (1976), acrescenta-se que, fonologicamente, conforme, entre outros, Givón (1990), o tópico (especificamente, o tópico deslocado à esquerda para este autor) pode ser caracterizado principalmente pela percepção de uma pausa subseqüiente e por um contorno entoacional separado do contorno entoacional do resto da sentença. ${ }^{4}$

No que concerne às regras que geram construções de tópico, Pontes (1987) observa que, na literatura americana de origem transformacionalista, os lingüistas costumam distinguir, entre as construções de tópico, aquelas que são geradas através de uma regra de Topicalização (Top) das que o são através da regra de Deslocamento à Esquerda (D.E.). Essa distinção foi estabelecida por Ross (1967), que se baseia essencialmente no fato de que, em D.E., aparece um pronome que ele chama de cópia e, em Top, esse pronome não aparece. De acordo com Ross, nos exemplos (5) e (6) do inglês, haveria Top e D.E. respectivamente :

(5) Beans I don't like.

"Feijão eu não gosto."

(6) The man my father works with in Boston, he's going to tell the police that...

"O homem com quem meu pai trabalha em Boston, ele vai contar à polícia que..." 
Não está no escopo deste estudo tratar dos processos que derivam construções de tópico, portanto, seguindo a linha de Li \& Thompson (1976), trataremos as construções de tópico geradas por Top ou por D.E. como um só tipo.

Assumiremos aqui que o tópico pode ser assim definido:

(i) do ponto de vista fonológico, como o elemento imediatamente seguido de pausa perceptual na sentença; ${ }^{5}$

(ii) do ponto de vista semântico/pragmático, como o elemento que carrega uma informação já referida no discurso (o centro da atenção, o "tópico" sobre o qual se discursa) e;

(iii) do ponto de vista sintático, como o elemento que ocupa uma posição sintática correspondente ao local imediatamente seguido por pausa perceptual (no caso de línguas que marcam tópico através de pausa subseqüente e por posição sintática), ou correspondente ao local de adjunção de uma marca morfológica identificadora de tópico (caso de línguas que marcam tópico morfologicamente e por posição sintática) ou ainda correspondente à posição específica que um elemento topicalizado deve ocupar na estrutura sintática do enunciado (línguas que marcam tópico apenas pela posição que esse elemento ocupa na sentença).

\section{As diferentes estratégias utilizadas pelas línguas na marcação de foco e tópico}

Quanto à marcação de foco nas línguas, pode-se dizer que as línguas escolhem diferentes maneiras para marcá-lo: morfologicamente (pela adição de alguma partícula ao elemento focalizado), sintaticamente (pela posição sintática ocupada pelo constituinte focalizado na sentença) e fonologicamente (pelo assinalamento de proeminência fonológica principal no elemento focalizado). As línguas podem utilizar uma ou mais de uma dessas estratégias para a marcação do foco.

Kidwai (1999) mostra que em hindi-urdu o foco contrastivo pode ser marcado sintaticamente, através da ocupação da posição pré-verbal pelo elemento focalizado, morfologicamente, pela focalização in situ via cliticização do elemento $h i$, e fonologicamente, através de marcação de acento contrastivo. Nenhuma destas estratégias de focalização se encontra em distribuição complementar em hindi-urdu, uma vez que todas as três podem ser utilizadas para marcar um mesmo constituinte, como mostra Kidwai (1999): 
(7) kitaab Ram-hii laayegaa (siitaa nahii). ${ }^{6}$

livro Ram-Emph trará Sita não

"Ram trará o livro, não Sita."

Em (7), o sujeito Ram é focalizado contrastivamente e o foco é identificado pela posição imediatamente pré-verbal em que o sujeito aparece (a ordem canônica em hindi-urdu é SOV), pelo acento contrastivo que esse elemento porta e pela cliticização enfática do elemento hii ao mesmo sujeito focalizado.

Por sua vez, no que concerne à marcação do tópico, assim como na marcação do foco, as línguas podem fazê-la morfologicamente (pela adição de alguma partícula ao elemento topicalizado), sintaticamente (pela posição sintática ocupada pelo constituinte topicalizado na sentença) e fonologicamente (através da percepção de pausa imediatamente após o elemento topicalizado). Assim como para a marcação de foco, as línguas também podem utilizar mais de uma dessas estratégias para a marcação do tópico.

Em tembé, por exemplo, Duarte (2003) observa que o elemento topicalizado pode ser identificado fonologicamente, pela percepção de uma pausa um pouco mais longa e pela presença de uma entoação mais plana após esse mesmo elemento; morfologicamente, pela possível adição da partícula enclítica -de, realização morfológica do traço [+ declarativo]; e, sintaticamente, através da ocupação da periferia esquerda na sentença. Como ilustração, eis o exemplo extraído de Duarte (2003, p. 149): ${ }^{7}$

(8) se-de pako Ana i-fu-n aqui-diz que banana Ana NC-comer-FOC

"Diz que aqui, banana, Ana comeu."

No exemplo, o advérbio se é topicalizado e essa topicalização pode ser identificada pela ocupação da periferia esquerda por esse elemento na sentença, pela cliticização da partícula enclítica - de a ele e por uma possível pausa após esse mesmo advérbio. Nota-se que a pausa no exemplo de Duarte pode ser identificada pela presença da vírgula após o elemento topicalizado na tradução para o português.

Tratemos agora das estratégias utilizadas por tzotzil, jakaltek, tembé, xavante, PB e PE na marcação e distinção tópico/foco. 


\subsection{A marcação e a distinção tópico/foco em tzotzil}

De acordo com Aissen (1992), tzotzil é uma língua VOS, pertence ao grupo das línguas Maya e é falada em Chiapas no México. Como as demais línguas Maya, tzotzil apresenta um sistema de concordância verbal ergativo e não apresenta marcação morfológica de caso nos NPs. Tzotzil também é uma língua pro-drop na qual pronomes não enfáticos não são pronunciados.

Conforme a mesma autora, tzotzil é uma língua que diferencia tópico de foco, sintaticamente (pela posição linear ocupada pelo elemento topicalizado ou focalizado na sentença e pela estrutura sintática que contém o elemento focalizado ou o elemento topicalizado), morfologicamente e prosodicamente (em termos de diferenciação quanto aos domínios prosódicos a que pertencem o elemento focalizado e o elemento topicalizado).

Aissen destaca que as línguas Maya podem distinguir foco e dois tipos de tópico: externo e interno. Quanto às estruturas sintáticas do foco e do tópico para as línguas Maya, Aissen propõe três estruturas sintáticas diferentes: uma para tópico interno (interno ao CP e especificador de IP), uma para tópico externo (externo ao $\mathrm{CP}$ e especificador de $\mathrm{CP}$ ) e outra para foco (interno ao IP e especificador de I'). Eis as estruturas propostas pela autora:
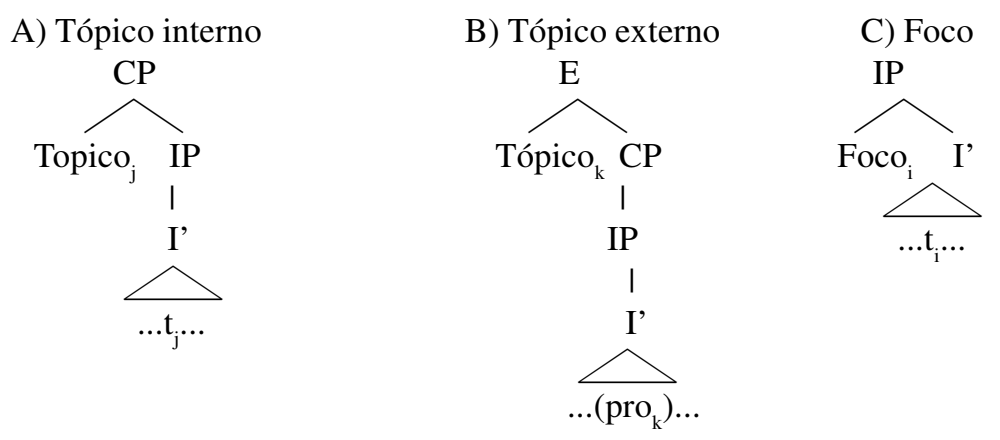

Segundo Aissen, tzotzil é uma língua que permite, além do foco, apenas tópico externo, portanto, nesta língua, apenas as estruturas B) e C) são utilizadas para representar estruturas sintáticas de tópico e foco respectivamente.

Em relação à posição linear ocupada na sentença, enquanto o elemento focalizado ocupa a posição pré-verbal, o elemento topicalizado ocupa a posição imediatamente inicial na sentença (cf. exemplos (10) e (11) para foco e tópico respectivamente). 
No que concerne à diferenciação morfológica entre foco e tópico, enquanto o tópico em tzotzil é (i) precedido por uma partícula $a$; (ii) quase sempre precedido por um determinante definido; e (iii) sempre seguido por uma partícula enclítica $-e$; o foco, nessa mesma língua, não é precedido pela partícula $a$, não é precedido imediatamente por nenhum determinante e não é seguido pela partícula enclítica $-e$, mas sim, pela partícula enclítica un. O exemplo (9) ilustra um caso de tópico em tzotzil e o exemplo (10) ilustra um caso de foco nessa mesma língua: ${ }^{8}$

(9) Contexto: Há um homem e uma mulher recém-casados.

a. a ti vinik-e ta=xlok'ech'el, ta=xbat ta=xxanav. TOPDET homem-ENC sai fora vai viaja

'O marido sai, ele vai, ele viaja.'

b. $\boldsymbol{a} \quad \boldsymbol{t} i \quad$ antz-e jun=yo' on ta $=x k o m \ldots$

TOP DET mulher-ENC feliz (adv) fica

'A mulher fica em casa feliz...'

(10) Contexto: Um indivíduo 1 está andando e encontra com um indivíduo 2 plantando milho no campo.

Indivíduo 1: "Eu estou plantando. Eu estou plantando pedras, eu estou plantando árvores",

Indivíduo 2: Pero chobtik tztz’un un. mas milho ele.planta ENC

'Mas era milho que ele estava plantando.'

No que diz respeito a questões prosódicas, Aissen, baseada em Hale \& Selkirk (1987), propõe o seguinte parâmetro de formação de sintagmas entoacionais (I) em tzotzil:

(11) $]_{X}^{\max }, X^{\max }$ não regido.

De acordo com Aissen, o tópico externo em tzotzil pertence a um sintagma entoacional diferente do sintagma entoacional que contém CP, uma vez que o tópico externo, conforme estrutura proposta em B) anteriormente, é uma projeção máxima não regida por CP. Já o foco pertence ao mesmo sintagma entoacional que contém IP, uma vez que não é uma projeção máxima e é regido por I', conforme estrutura proposta em C). Assim, a partícula enclítica $-e$ segue imediatamente o elemento topicalizado, sendo adjungida à fronteira direita do sintagma entoacional que contém esse elemento. Já a partícula enclítica-un não 
segue imediatamente o elemento focalizado necessariamente, pois é adjungida à fronteira direita do sintagma entoacional que contém esse elemento e tal fronteira não coincide necessariamente com a fronteira direita da posição ocupada pelo mesmo elemento focalizado na sentença.

Em relação à marcação e distinção fonológica de foco e tópico, por algum tipo de proeminência, contorno entoacional ou pausa, acrescenta-se que, no trabalho de Aissen, não há menção alguma sobre tal fato.

Em relação à estrutura semântica, o tópico e o foco também se distinguem em tzotzil. Enquanto o foco apresenta uma estrutura semântica composta por uma asserção (elemento focalizado) e uma pressuposição (restante da sentença que não contém o elemento focalizado), o tópico não apresenta essa mesma estruturação informacional. O tópico é usado para chamar a atenção do ouvinte para algum participante identificável no discurso e, então, é feita alguma asserção sobre esse participante. Tal participante é o tópico do discurso corrente até que outra entidade seja introduzida como tópico.

\subsection{A marcação e a distinção tópico/foco em jakaltek}

Jakaltek é também uma língua Maya, parente muito próxima de tzotzil e é falada no departamento de Huehuetenago na Guatemala.

Assim como tzotzil, jakaltek também é uma língua que diferencia as funções pragmáticas de tópico e foco sintaticamente, prosodicamente e morfologicamente.

Em relação ao tópico, somente o tópico externo é permitido nessa língua. Portanto, as estruturas de tópico e foco propostas por Aissen para jakaltek são as mesmas propostas para tópico e foco em tzotzil (estruturas B) e C) apresentadas anteriormente).

No que diz respeito à diferenciação entre foco e tópico com relação à estrutura semântica, emjakaltek, podem ser assumidas as mesmas afirmações feitas para tzotzil.

Tópico e foco também são distinguidos em jakaltek pela posição linear que esses dois elementos ocupam na sentença. Jakaltek é uma língua VSO na qual elementos topicalizados ocupam a posição imediatamente inicial nas sentenças e elementos focalizados ocupam a posição pré-verbal (cf. exemplos (12) e (13) para constatação dessa afirmação).

Quanto à caracterização morfológica, destaca-se que o foco em jakaltek pode: (i) opcionalmente ser precedido por uma partícula clivada ha ( $h a$ é usada obrigatoriamente quando o elemento focalizado é um pronome pessoal); (ii) 
apresentar um sufixo $n i$ anexado ao verbo quando o sujeito de um verbo transitivo é focalizado. ${ }^{9}$ Já o tópico em jakaltek não é precedido pela partícula clivada $h a$, a forma de foco no verbo não é utilizada, mesmo quando o tópico corresponde ao sujeito de verbo transitivo, e um pronome co-referencial com o tópico ocorre na posição de onde o tópico foi movido, à luz de uma análise de movimento. Um pronome nunca ocorre na posição da qual o foco é movido. As afirmações contidas neste parágrafo podem ser constatadas nos exemplos (12) e (13) abaixo, referentes a foco e tópico em jakaltek respectivamente: ${ }^{10}$

(12) $H a^{\prime}$ naj $x$-maq-ni $i x$. cleft ele ASP-bater-FOC ela "É ele que bate nela."

(13) Naj Pel s-maq naj ix. CLS Pedro E3-bater ele ela "Pedro, ele bate nela."

No que tange a questões prosódicas, jakaltek apresenta uma partícula enclítica que ocorre em condições muito semelhantes às que as partículas un e $-e$ ocorrem em tzotzil, cf. Aissen (1992).

Em jakaltek, a partícula enclítica an ocorre imediatamente depois de um tópico que contém um pronome de primeira pessoa, mas não depois de um foco. Aissen postula que em jakaltek a partícula an é adjungida à fronteira direita do sintagma entoacional que contém o elemento focalizado ou o elemento topicalizado. De acordo com Aissen, o sintagma entoacional em jakaltek é formado pelo mesmo parâmetro proposto por ela para a formação de sintagma entoacional em tzotzil. Assim, conforme as estruturas sintáticas B) e C) propostas respectivamente para tópico e foco na seção 2.2., pela aplicação do parâmetro de formação de sintagma entoacional (cf. (11)), o tópico em jakaltek é separado do que o segue no enunciado por uma fronteira de sintagma entoacional, enquanto o foco não. Os exemplos (14) referente a tópico e (15) referente a foco, apresentados logo a seguir, ilustram o exposto: ${ }^{11}$

(14) W-uxhtaj an [sloq ho' no' cheh k'ej'inh tu'] ('an). meu-irmão ele.comprou ele CLS cavalo preto aquele "Meu irmão, ele comprou aquele cavalo preto." 
(15) [W-uxhtaj(*an) x-loq-ni hune' no' cheh k'ej'inh tu']an. meu-irmão ASP-comprar-FOC um CLS cavalo preto aquele

"Foi meu irmão que comprou aquele cavalo preto."

Quanto à marcação e distinção fonológica de tópico e foco por proeminência, contorno entoacional ou pausa, assim como foi observado para tzotzil, também para jakaltek, não se encontra, no trabalho de Aissen, nenhuma menção sobre o fato de jakaltek marcar e distinguir (ou não) tópico e foco por qualquer tipo de proeminência, contorno entoacional ou pausa.

\subsection{A marcação e a distinção tópico/foco em tembé}

Tembé é uma língua indígena brasileira do tronco Tupi, pertencente à família Tupi-Guarani. As aldeias Tembé se dividem em dois blocos dentro da reserva indígena denominada Alto Rio Guamá, a sudeste do estado do Pará: (i) o primeiro se situa na margem direita do rio Guamá e; (ii) o segundo se situa na margem do rio Gurupi, fronteira com o estado do Maranhão e Pará. De acordo com Duarte (2003), a língua tembé compartilha traços fonológicos e de estrutura com as línguas tapirapé, avá-canoeiro, assuriní do Tocantins (akuáwa), suruí do Tocantins (mujetíre), parakanã e guajajara e compartilha traços gramaticais, como a ordem VSO em orações principais e a ocorrência da ordem V-auxiliar com o auxiliar flexionado, com esta última. Vale destacar, conforme o mesmo autor, que tembé e guajajara são praticamente variantes dialetais de uma mesma língua, de tal maneira que os índios Tembé e Guajajara se consideram um só povo, autodenominando-se Tenetehara, que significa "a gente, os índios em geral".

Fonologicamente, Duarte (2003, p. 146) caracteriza e distingue foco de tópico em tembé da seguinte maneira: "em geral, o foco recebe o pico entoacional, enquanto o tópico vem separado do comentário por meio de uma pausa mais longa e entoação mais plana".

Morfologicamente, a distinção foco/tópico se dá em tembé na medida em que, em sentenças com elemento topicalizado, a partícula enclítica - $d e$, realização morfológica do traço [+ declarativo], pode ser adjungida ao elemento topicalizado, enquanto o elemento focalizado (no trabalho de Duarte, especificamente, o objeto) desencadeia um padrão de flexão verbal especial através da adjunção do prefixo acusativo $i$ - e do sufixo - $n$ ao verbo.

Assim como em tzotzil e jakaltek, tópico e foco também são distinguidos em tembé pela posição linear que esses dois elementos ocupam na sentença. Em 
tembé, a ordem não marcada é VSO ( SVO) na qual elementos topicalizados são deslocados para a periferia esquerda das sentenças, enquanto elementos focalizados são deslocados para uma posição de foco (posição imediatamente inicial na sentença, quando não há elemento topicalizado na mesma sentença, e posição imediatamente posterior à posição de tópico, quando esse elemento também está contido na sentença). Os exemplos (16) de tópico, (17) de foco no objeto e (18) de foco e tópico na mesma sentença, apresentados logo abaixo, confirmam o que foi exposto quanto à caracterização morfológica de tópico e foco e quanto à posição linear ocupada por esses dois elementos nas sentenças de tembé: ${ }^{12}$

(16) Pikidipape kwehe ru-dapi-api a?e dawar.

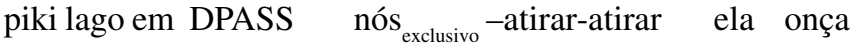

"No lago do piki, (nós) atiramos na onça (ela, onça a que estamos nos referindo)."

(17) upawiwira teko i-mua2ay kuri toda madeira a gente 3-marcar então

"Toda a madeira, a gente marca então."

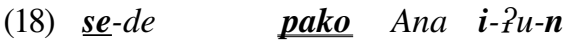
aqui-diz que banana Ana NC-comer-FOC

"Diz que aqui, banana, Ana comeu."

Quanto às estruturas sintáticas de sentenças com elemento topicalizado ou focalizado, Duarte postula que esses elementos seriam deslocados para uma posição especial da sentença, periferia esquerda da sentença, respectivamente Spec,TopPe Spec,FocP, para checar os traços fortes de tópico e foco nessas respectivas posições. O mesmo autor ainda nota que, em sentenças com sintagmas focalizados ou topicalizados, não há movimento do verbo, uma vez que apenas o preenchimento de Spec,TopPe Spec,FocPé suficiente para satisfazer os critérios de foco e tópico. Diferentemente de tembé, em húngaro, conforme Puskas (1997), é necessário que o verbo esteja no núcleo de FocP para a verificação do traço de foco dos constituintes focalizados. Se o verbo não estiver adjacente ao constituinte focalizado em húngaro, a sentença se torna agramatical.

Como exemplo do que foi exposto, eis a estrutura proposta por Duarte para a sentença com elemento focalizado e elemento topicalizado apresentada em (18):

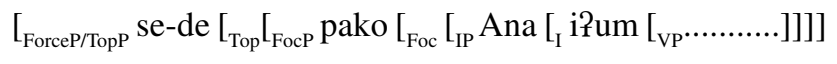


Faz-se necessário acrescentar que, no trabalho de Duarte, não se encontra nenhum comentário a respeito do fato de tembé marcar e distinguir (ou não) tópico e foco prosodicamente, no que concerne a domínios prosódicos.

\subsection{A marcação e a distinção tópico/foco em xavante}

Xavante, assim como tembé, é uma língua indígena brasileira. A língua xavante pertence à família Jê, principal família do tronco Macro-Jê. Junto com o xavante (Jê Central), há mais oito línguas ainda faladas que são classificadas como membros da família Jê. São elas: timbira, apinayé, kayapó, panará e suya (Jê Setentrional), xerente (Jê Central), kaingang e xokléng (Jê Meridional). O povo Xavante vive hoje na parte leste do estado de Mato Grosso, região Centro-Oeste do Brasil, em uma área de cerrado. Conforme Rodrigues (1999), eles hoje possuem uma população de cerca de nove mil pessoas distribuídas em seis reservas diferentes: São Marcos, Sangradouro, Marechal Rondon, Parabubure, Areões e Pimentel Barbosa.

Segundo Oliveira (2002), a ordem básica da oração em xavante é SOV, podendo também ocorrer as ordens OSV e SVO, esta última sendo apenas a tradução livre do português para o xavante. A mesma autora acrescenta que, quando o objeto aparece deslocado à esquerda da sentença (ordem OSV), ele possui uma marcação pragmática, que codifica um elemento topicalizado ou focalizado, havendo uma certa dificuldade em saber a diferença entre tópico e foco nessa língua, pois não há, segundo Oliveira, nenhuma marcação morfológica clara identificando-os. Portanto, no que diz respeito à posição linear ocupada pelos elementos topicalizados ou focalizados nas sentenças em xavante, conclui-se que eles ocupam a posição correspondente à periferia esquerda da sentença.

Oliveira destaca que a diferenciação tópico/foco em xavante se dá por meio da interpretação semântica, pelo contexto: o tópico constituindo informação velha, sendo retomado na oração, e o foco constituindo informação nova. As sentenças em (20) e (21) apresentadas a seguir e extraídas de Oliveira, respectivamente, sentença com elemento topicalizado e com elemento focalizado em xavante, confirmam as afirmações apresentadas: ${ }^{13}$

Contexto - Sentença imediatamente anterior: "Há muito tempo atrás não havia fogo." 
(20) uñama 'ãna te're dañimi 'waara.

fogo sem $3^{\text {a }}$ cont. pessoas viver

"As pessoas viviam habitualmente sem fogo."

(21) wedeñi wa.hu.tsi te date 're hu.ri...

casca de madeira somente $3^{\text {a }}$ pessoa progr.cont. comer...

"As pessoas comiam somente casca de madeira..."

Quanto ao critério morfológico de distinção foco/tópico, embora Oliveira não tenha identificado qualquer marca morfológica caracterizadora de foco ou tópico nos seus dados de xavante, Burgess (1987) nota, em alguns casos, o uso do enclítico-hãapós um constituinte topicalizado e ouso do enclítico quantificacional -tsi (só/somente) em sintagmas nominais que contrastam com o tópico anterior (foco contrastivo) - cf. também o exemplo (22) de Oliveira. ${ }^{14}$ Eis os exemplos apresentados por Burgess (1987, p. 31), respectivamente, de tópico e sintagma nominal que contrasta com tópico anterior (foco contrastivo):

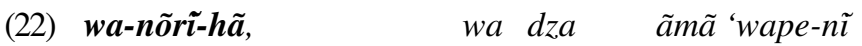
nós-grupo-especificador nós futuro lá o-levar "Nosso grupo, nós o levaremos lá."

Contexto - Após um parágrafo sobre Dominga, um texto continua assim:

(23) Nãriñäha-tsi tê dza wara. Nharinha-só ela futuro voar

"Só Nharinha vai de avião." (não Dominga)

No que se refere às estruturas sintáticas de sentenças com elemento topicalizado e de sentenças com elemento focalizado, assim como Duarte (2003) propõe para tembé, Oliveira propõe que elementos topicalizados e focalizados em xavante se deslocam para a periferia esquerda das sentenças, respectivamente, para as posições Spec,TopPe Spec,FocP, para a checagem de traços de tópico e foco. A mesma autora acrescenta que estes traços são checados na relação especificador núcleo. Eis as estruturas sintáticas propostas por Oliveira para as sentenças (21), com elemento topicalizado, e (22), com elemento focalizado, apresentadas anteriormente:

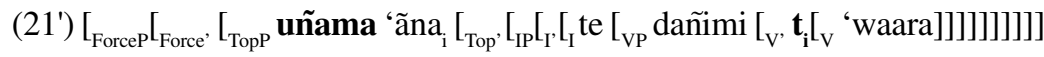

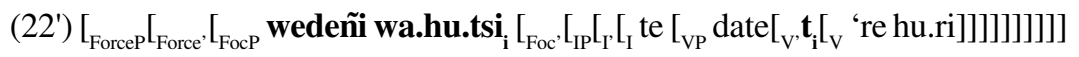


Oliveira ainda destaca que há em xavante também um outro tipo de tópico, que está deslocado à esquerda da partícula interrogativa $e$, a qual é gerada no sintagma de Força e dá à sentença seu valor interrogativo: ${ }^{15}$

(24) Ba'airi e te hödzu 'õ di Bakairi int $3^{\text {a }}$ picar neg. estat.

"Ele não picou o Bakairi?"

A referida autora acrescenta que esse tipo de tópico é um simples deslocamento à esquerda e não um Hanging Topic, nos termos de Benincá (2001). Com o Hanging Topic, o sintagma nominal não é gerado como complemento do verbo, e sim na própria estrutura do sintagma complementizador. Como na língua xavante a ordem básica é SOV, Oliveira analisa que o objeto $B a$ 'airi foi gerado na posição de complemento do verbo e, depois, foi movido para a posição acima do sintagma de Força, consistindo, assim, num simples deslocamento à esquerda, e não propriamente em um Hanging Topic.

Embora Oliveira conclua que o tipo de tópico do exemplo (25) seja um simples deslocamento à esquerda, diferente de Hanging Topic, ela sugere que a posição DiscP (posição acima do sintagma de Força), proposta por Benincá (2001) para Hanging Topic, seria uma boa posição para abrigar este tipo de sintagma deslocado à esquerda da partícula interrogativa $e$ em xavante:

(24') [DiscP Ba'airi [Disc' [ForceP[Force'[Force $e$ [TopP[Top' [FocP[Foc' [IP hödzu 'õ di]]]]]]]]]]

Acrescenta-se que nos trabalhos de Oliveira e Burgess não se encontra nehuma menção sobre o fato de o xavante marcar ou não foco e tópico fonologicamente, por exemplo, por proeminência, contorno entoacional ou pausa, e prosodicamente (em termos de domínios prosódicos).

\subsection{A marcação e a distinção tópico/foco em PB e em PE}

PB e PE são duas variedades de português, uma falada no Brasil e a outra falada em Portugal, respectivamente.

Galves (1998), baseada na distinção Língua-Externa (Língua-E) / LínguaInterna (Língua-I) proposta por Chomsky (1985), afirma que, do ponto de vista da Língua-I, ou seja, da gramática, o PE e o PB são duas línguas diferentes. ${ }^{16}$ 
A afirmação feita por Galves é corroborada por ocorrências peculiares na sintaxe de $\mathrm{PB}$ que, se presentes em PE, produziriam enunciados agramaticais nesta variedade. $\mathrm{Ou}$, pelo fato de, em alguns casos, apesar de os enunciados serem superficialmente comuns às duas variedades, não receberem a mesma interpretação. A autora aponta as seguintes ocorrências gramaticais próprias de PB:

1. A gramática brasileira substitui o clítico acusativo de terceira pessoa pelo pronome tônico, e por uma categoria vazia de natureza pronominal. Ex.1: VI ELE ontem na rua. Ex.2: (falando dos pastéis) O rapaz QUE TROUXE da pastelaria era o teu afilhado. ${ }^{17}$

2. A gramática brasileira limita a posição dos clíticos à adjacência do verbo temático. Ex.: Agora não tinha ME lembrado. ${ }^{18}$

3. A gramática brasileira produz um sujeito nulo de interpretação indeterminada, que requer certos contextos para receber uma interpretação referencial específica, contrariamente ao PE ou a outras línguas de sujeito nulo. Ex.: (referindo-se a pessoa indeterminada) Não usa mais freio. ${ }^{19}$

4. A gramática brasileira produz estruturas em que um objeto assume função de sujeito sem que nenhuma marca morfológica seja necessária para legitimar essa mudança. Ex.: A balança está consertando. ${ }^{20}$

Neste trabalho assumiremos o ponto de vista de Galves, segundo o qual, PB e PE podem ser considerados duas línguas diferentes.

Quanto à distinção tópico/foco, pode-se afirmar que tanto $\mathrm{PB}$ quanto $\mathrm{PE}$ distinguem tópico e foco fonologicamente, prosodicamente e sintaticamente.

No que diz respeito ao critério morfológico, diferentemente de tzotzil, jakaltek, tembé e xavante, PB e PE não marcam elementos focalizados ou topicalizados através da adjunção de partículas clíticas, codificadoras de topicalização ou focalização, a esses elementos.

Quanto ao critério fonológico de distinção tópico/foco em PB e em PE, cabe acrescentar que, tanto em PB quanto em PE, o elemento topicalizado porta proeminência fonológica e geralmente é seguido de pausa, ocorrência que delimita fronteiras de sintagmas entoacionais, conforme a abordagem de Nespor \& Vogel (1986). Já o elemento focalizado em PB e em PE nãoé seguido de pausa, mas necessariamente porta a proeminência fonológica principal da sentença (cf. FROTA, 2000 para PE; GONÇALVES, 1997 para PB; e FERNANDES, 2007 para PB e PE). 
Em relação à distinção prosódica entre tópico e foco em PE e PB, observa-se que, nessas duas variedades de português, tópico e foco são distintos em relação ao domínio prosódico a que pertencem. Conforme Gonçalves (1997), em PB, o elemento focalizado corresponde a um sintagma fonológico (f) da sentença e o elemento topicalizado corresponde a um sintagma entoacional (I) independentemente do resto da sentença. ${ }^{21}$

EmPE, de acordo com Frota (2000), enunciados com elemento topicalizado podem ser mapeados em dois sintagmas entoacionais, um contendo somente $\mathrm{o}$ elemento topicalizado e outro contendo o resto do enunciado; já enunciados contendo elemento focalizado são mapeados em um único sintagma entoacional, sendo que o elemento focalizado pertence ao mesmo sintagma entoacional que contém o restante do enunciado. As mesmas considerações podem ser feitas para o PB, conforme o trabalho de Gonçalves (1997). Os exemplos (25) e (26) de PB, respectivamente de foco e tópico e extraídos de Gonçalves, e os exemplos (27) e (28) de PE, respectivamente de foco e tópico e extraídos de Frota, confirmam o exposto: ${ }^{22}$

EmPB:

Contexto possível: Eu enviei o telegrama pra Ana. O que você enviou pra Ofélia?

(26) $[[\underline{\text { A carta }}] \phi[\mathrm{eu}] \phi[$ enviei $] \phi[$ pra Ofélia $] \phi] \mathrm{I}$

Contexto possível A: Dois homens estão conversando sobre uma carta e um telegrama que foram enviados a duas mulheres. Um deles diz: O telegrama, eu enviei pra Ana. O mesmo indivíduo continua sua fala:

(27) $[[$ A carta $\phi] \mathrm{I}[[\mathrm{eu}] \phi[$ enviei $] \phi[$ pra Ofélia $] \phi] \mathrm{I}$

EmPE:

(28) Quem ofereceu especiarias aos jornalistas?

$[[\underline{\text { As angolanas }}] \phi$ [ofereceram especiarias $] \phi[$ aos jornalistas $] \phi] I$

(29) Contexto B: Angolanas e moçambicanas exiladas em Portugal resolveram presentear os jornalistas com ofertas provenientes dos seus países. Quanto às moçambicanas, trouxeram plantas exóticas.

$[[$ As angolanas $] \phi] I[[$ ofereceram especiarias $] \phi[$ aos jornalistas $] \phi] I$

Nos exemplos (25) e (27) de foco em PB e PE respectivamente, pode-se ver que os constituintes deslocados "a carta" e "as angolanas" são focalizados, pois trazem as informações novas, a respeito do que foi enviado "à Ofélia" e a respeito de "quem ofereceu especiarias aos jornalistas", requeridas respectivamente pelas 
perguntas "O que você enviou pra Ofélia?" e "Quem ofereceu especiarias aos jornalistas?”. Por outro lado, nos exemplos (26) e (28) de tópico em PB e em PE, os mesmos constituintes deslocados ("a carta" e "as angolanas") agora carregam informações já referidas no contexto que antecede os enunciados contendo esses dois tópicos, respectivamente, contextos Ae $\mathrm{B}$ dos exemplos mencionados.

Com relação ao critério sintático, observa-se que, em PE, o tópico pode aparecer in situ ou deslocado de sua posição argumental onde é deixada uma lacuna (cf. DUARTE, I., 1987; 1996 sobre tópico deslocado em PE). Isso pode ser constatado pelos exemplos (29) de tópico in situ e (30) de tópico deslocado em PE, extraídos de Frota (2000):

(29) Contexto: Jovens africanas a estudar em Portugal apresentaram ontem as suas ofertas a jornalistas portugueses.

As angolanas ofereceram especiarias, aos jornalistas. (tópico in situ)

(30) Contexto: Havia imensa gente a receber ofertas de jovens angolanas radicadas em Portugal. Sabes se os jornalistas foram presenteados?

Aos jornalistas $_{i}$, as angolanas ofereceram especiarias ${ }_{-i}$. (tópico deslocado)

Já em PB, baseando-nos no trabalho de Pontes (1987) sobre tópico em $\mathrm{PB}$, é possível afirmar que o tópico aparece freqüentemente deslocado de sua posição argumental, como mostra o exemplo extraído de Pontes (1987, p. 14):

(31) A. Tô procurando a Vanda.

B. A Vanda ${ }_{i}$ eu acho que ${ }_{-i}$ tá dando aula.

Quanto à marcação de foco através da posição sintática ocupada pelo elemento na sentença, nota-se que PE pode fazer o uso da posição final da sentença, além de proeminência fonológica, para a marcação de foco de informação. Já em PB, este mesmo tipo de foco, a não ser em contextos específicos, é marcado essencialmente por proeminência fonológica, da mesma maneira que o foco contrastivo. ${ }^{23}$

Nota-se que PE pode se utilizar de diferentes estratégias de focalização para distinguir diferentes tipos de foco. $\mathrm{O}$ foco contrastivo em PE é marcado exclusivamente na fonologia (assinalamento de proeminência fonológica). Já o foco de informação pode ser marcado somente fonologicamente (assinalamento de proeminência fonológica) - cf. Frota (2000), ou sintática e fonologicamente, através da posição ocupada pelo elemento focalizado (última posição na sentença -cf. COSTA, 1998; 2004), posição na qual é assinalado o acento principal de sentença 
neutra à palavra fonológica cabeça do último sintagma fonológico do sintagma entoacional (cf. FROTA, 2000). Oexemplo (32) de foco contrastivo de Frota (2000) e o exemplo (33) de foco de informação, extraído de Costa (1998), ilustram o exposto:

(32) Foram as moçambicanas que ofereceram especiarias aos jornalistas? As angolanas ofereceram especiarias aos jornalistas.

(33) Quem partiu a janela?

a. Partiu a janela o Paulo.

Já em PB não se observam as mesmas estratégias que foram observadas para PE, uma vez que tanto o foco contrastivo quanto o foco de informação em PB são marcados essencialmente pela proeminência fonológica principal de sentença assinalada ao elemento focalizado. Note que, se utilizarmos o mesmo tipo de exemplo que aparece em (33) para PB, o resultado seria agramatical em PB, como pode ser atestado em (34), em que a sentença gramatical é a apresentada em (34b) com o sujeito precedendo o verbo e portando a proeminência principal da sentença:

(34) Quem quebrou a janela?

a. *Quebrou a janela o Paulo.

b. O Paulo quebrou a janela.

Portanto, quanto à distinção tópico/foco através da posição ocupada por esses elementos na sentença, constata-se que o tópico em PB e PE pode ser marcado pela ocupação da periferia esquerda da sentença (caso de tópico deslocado). Todavia, apenas em PE o foco de informação pode ser marcado de maneira geral pela posição sintática ocupada na sentença (última posição) e, em $\mathrm{PB}$, a marcação de foco através de posição sintática é mais rara e restrita-cf. nota 23 deste mesmo trabalho. ${ }^{24}$

\section{Agrupamento das línguas tzotzil, jakaltek, tembé, xavante, PB e PEquanto às estratégias utilizadas na marcação de tópico e foco}

De acordo com o que foi apresentado a respeito da distinção entre tópico e foco em tzotzil, jakaltek, tembé, xavante, PB e PE na seção 2 deste trabalho, é possível verificar que as seis línguas marcam distintivamente esses dois fenômenos lingüísticos - ainda que os trabalhos nos quais nos baseamos no 
desenvolvimento da seção 2 sejam um tanto quanto divergentes no que diz respeito a certos aspectos das análises realizadas (por exemplo, no caso das análises sintáticas apresentadas pelos diferentes autores). Essa distinção é feita através de marcação morfológica (pela adjunção de partículas diferentes ao elemento topicalizado ou focalizado, como se verifica em tzotzil e jakaltek), sintática (pela representação de estruturas sintáticas diferentes para enunciados contendo elementos focalizados e enunciados contendo elementos topicalizados, como em tzotzil, jakaltek, tembé exavante), fonológica (através de assinalamento de proeminência fonológica principal da sentença no foco e pela percepção de uma pausa seguindo o tópico, como em tembé, PB e PE), ou prosódica, em termos de domínios prosódicos (pelo fato de tópico e foco apresentarem diferenças no que concerne aos domínios prosódicos aos quais pertencem, como em tzotzil, jakaltek, PB e PE).

Quanto às estratégias utilizadas pelas mesmas línguas já referidas para a marcação dos dois fenômenos lingüísticos aqui abordados, é possível inferir um agrupamento linguiístico entre elas com base nas características elencadas no quadro 1:

QUADRO 1

Marcação e distinção foco/tópico em tzotzil, jakaltek, tembé, xavante, PB e PE

\begin{tabular}{|c|c|c|c|c|c|c|}
\hline Línguas & Tzotizil & Jakaltek & Tembé & Xavante & $\mathrm{PB}$ & $\mathrm{PE}$ \\
\hline $\begin{array}{l}\text { Marcação morfológica } \\
\text { de foco }\end{array}$ & $\mathrm{x}$ & $\mathrm{x}$ & $\mathrm{x}$ & $\mathrm{x}$ & - & - \\
\hline $\begin{array}{l}\text { Marcação sintática de } \\
\text { foco (posição ocupada } \\
\text { na sentença) }\end{array}$ & $\mathrm{x}$ & $\mathrm{x}$ & $\mathrm{x}$ & $\mathrm{x}$ & - & $\mathrm{x}$ \\
\hline $\begin{array}{l}\text { Marcação fonológica } \\
\text { de foco por proemi- } \\
\text { nência fonológica }\end{array}$ & $?$ & $?$ & $\mathrm{x}$ & $?$ & $\mathrm{x}$ & $\mathrm{x}$ \\
\hline $\begin{array}{l}\text { Distinção entre tipos } \\
\text { de foco pela utilização } \\
\text { de estratégias de foca- } \\
\text { lização diferentes }\end{array}$ & $?$ & $?$ & $?$ & $?$ & - & $\mathrm{x}$ \\
\hline $\begin{array}{l}\text { Marcação morfológica } \\
\text { de tópico }\end{array}$ & $\mathrm{x}$ & $\mathrm{x}$ & $\mathrm{x}$ & $\mathrm{x}$ & - & - \\
\hline $\begin{array}{l}\text { Marcação sintática de } \\
\text { tópico (posição ocupa- } \\
\text { da na sentença) }\end{array}$ & $\mathrm{x}$ & $\mathrm{x}$ & $\mathrm{x}$ & $\mathrm{x}$ & $\mathrm{x}$ & $\mathrm{x}$ \\
\hline $\begin{array}{l}\text { Marcação fonológica } \\
\text { do tópico por percep- } \\
\text { ção de pausa após esse } \\
\text { elemento }\end{array}$ & ? & $?$ & $\mathrm{x}$ & ? & $\mathrm{x}$ & $\mathrm{x}$ \\
\hline
\end{tabular}


Através da observação do quadro constata-se que:

(i) tzotzil e jakaltek se comportam semelhantemente quanto aos fenômenos de focalização e topicalização, comportamento que pode ser explicado pela proximidade em parentesco entre essas duas línguas;

(ii) xavante e tembé marcam foco e tópico morfológica e sintaticamente (posição ocupada na sentença). Além de marcar foco e tópico morfológica e sintaticamente, tembé também os marca fonologicamente;

(iii) $\mathrm{PE}$ e PB, mesmo sendo línguas muito próximas, distinguem-se quanto aos aspectos de "marcação sintática de foco (posição ocupada na sentença)" e "distinção entre tipos de foco pela utilização de estratégias de focalização diferentes";

(iv) PE e PB se distinguem de tzotzil, jakaltek, tembé e xavante por não marcar foco e tópico morfologicamente, por adjunção de partículas afixais aos elementos focalizado e topicalizado;

(v) em PE é feita a distinção de tipos de foco através do uso de diferentes estratégias de focalização e, apenas em PB, com exceção de certos casos, cf. nota 23 deste mesmo trabalho, não é permitida a marcação de foco pela posição ocupada pelo elemento focalizado na sentença.

O estudo da focalização e da topicalização nas línguas permite-nos estabelecer uma diferenciação entre elas.

PB ePE se distinguem de tzotzil, jakaltek, tembée xavante quantoà marcação de tópico e foco, uma vez que as duas primeiras não marcam tópico e foco morfologicamente (pela adjunção de partículas afixais) como o fazem as quatro últimas. Tembé se distingue das demais línguas quanto aos critérios de marcação de tópico e foco pelo fato de podermos afirmar, com certeza, que apenas ela, entre as línguas abordadas neste trabalho, marca tópico e foco pelos três critérios apresentados no quadro 1: morfológico, sintático (posição ocupada na sentença) e fonológico. Acrescenta-se que apenas para PE é sabido haver a distinção entre diferentes tipos de foco através do uso de diferentes estratégias de focalização.

Nota-se, inclusive, que é possível distinguir línguas muito próximas como PB e PE quanto ao fenômeno da focalização. Enquanto PE distingue tipos de foco através de diferentes estratégias de focalização e pode marcar foco de informação por posição sintática, PB marca foco, em geral, essencialmente por proeminência fonológica principal de sentença. 


\section{Considerações finais}

No presente trabalho apresentamos uma caracterização de foco e tópico e contemplamos, de maneira especial, as estratégias utilizadas pelas línguas tzotzil, jakaltek, tembé, xavante, PB e PE na marcação e distinção entre foco e tópico.

Através das semelhanças e diferenças quanto à escolha das estratégias utilizadas na marcação de foco e tópico, é possível propor um agrupamento lingüístico para as línguas já mencionadas.

Cabe notar que, embora essas línguas pertençam a troncos lingüísticos diferentes, é possível propor um agrupamento língüístico para elas, baseando-nos em suas diferenças e semelhanças, uma vez que apresentam características comuns às línguas naturais, em especial, no que tange ao assunto tratado neste trabalho: marcação e distinção de tópico e foco.

Observamos que, ainda que de maneira diferente (seja fonologicamente, prosodicamente, sintaticamente ou morfologicamente), todas as línguas abordadas neste trabalho distinguem foco e tópico.

Também constatamos que, além da possibilidade de distinção entre as línguas através das estratégias utilizadas por elas na marcação e distinção entre foco e tópico, é possível distinguir mesmo línguas muito próximas como PB e PE no que concerne ao comportamento perante o fenômeno da focalização, visto que PE distingue tipos de foco através do uso de diferentes estratégias de focalização e PB marca foco em geral essencialmente pelo assinalamento de proeminência fonológica principal da sentença.

\section{Notas}

${ }^{1}$ Este trabalho é resultado do desenvolvimento de uma qualificação de área, um dos requisitos exigidos pelo Programa de Pós-Graduação do Instituto de Estudos da Linguagem da Universidade Estadual de Campinas para a obtenção do título de doutor. Agradeço ao meu orientador de qualificação de área, Angel Corbera Mori, bem como aos demais membros da banca de qualificação, Maria Bernadete Marques Abaurre e Frantomé Bezerra Pachêco pelas sugestões e críticas feitas a versões preliminares deste trabalho. Pelas sugestões, comentários e críticas feitas a uma versão prévia deste artigo, meus agradecimentos vão também para os pareceristas anônimos da Revista de Estudos da Linguagem que avaliaram tal versão. Agradeço ainda à Fundação de Amparo à Pesquisa do Estado de São Paulo pelo apoio financeiro ao desenvolvimento da pesquisa de doutorado "Ordem, focalização e 
preenchimento em português: sintaxe e prosódia" (processo Fapesp 03/13938-5), no âmbito da qual este trabalho foi realizado.

${ }^{2}$ Os termos do inglês são extraídos de Ladd (1996).

${ }^{3}$ Para efeitos de simplificação, neste trabalho, não trataremos da caracterização do foco através da atribuição de eventos tonais ao elemento focalizado, ou ainda da caracterização deste elemento através de duração segmental.

${ }^{4}$ Cabe acrescentar que, assim como o foco, o tópico também pode portar proeminência fonológica, mas, diferentemente do primeiro, não é a proeminência fonológica o principal correlato fonológico que caracteriza o tópico.

${ }^{5}$ Para efeitos de simplificação, neste trabalho não trataremos da caracterização do tópico através da atribuição de eventos tonais e através da presença de um contorno entoacional específico, nem da caracterização através da duração segmental do elemento topicalizado.

${ }^{6}$ Elemento em negrito: receptor de acento contrastivo na sentença; Emph: partícula enfática.

${ }^{7}$ Elemento em negrito: elemento topicalizado; NC: prefixo que marca a nãoadjacência do complemento da posposição, do objeto do verbo transitivo, do possuidor nos sintagmas genitivos e do sujeito do verbo intransitivo nas orações subordinadas com os complementizadores $p$ « e mehee; FOC: núcleo do sintagma de foco.

${ }^{8}$ Os exemplos em (9) e (10) foram extraídos de Aissen (1992). Em tais exemplos, elementos em negrito representam elementos topicalizados ou focalizados; TOP representa partícula que antecede o elemento topicalizado; DET representa determinante; ENC, partícula enclítica; e adv, advérbio.

${ }^{9}$ Em jakaltek, também é empregada uma forma especial de foco no verbo quando o sujeito de um verbo transitivo é questionado ou relativizado (cf. Aissen, 1992).

${ }^{10}$ Os exemplos em (12) e (13) foram extraídos de Aissen (1992). Nestes exemplos, CLEFT representa partícula clivada; ASP representa partícula aspectual; FOC, partícula que marca foco; CLS, classificador de nome; E, ergativo; 3 , terceira pessoa.

${ }^{11}$ Exemplos extraídos de Craig (1977).

${ }^{12}$ Os exemplos em (16), (17) e (18) foram extraídos de Duarte (2003). Convenções utilizadas nos exemplos: $\mathrm{DPASS}=$ passado distante $3=$ terceira pessoa; $\mathrm{NC}=$ prefixo que marca a não-adjacência do complemento da posposição; do objeto do verbo transitivo; do possuidor nos sintagmas genitivos e do sujeito do verbo intransitivo nas orações subordinadas com os complementizadores $p$ « e mehe; FOC = núcleo do sintagma de foco; elementos em negrito e com um único sublinhado = elementos topicalizados; elementos em negrito e com duplo sublinhado $=$ elementos focalizados 
${ }^{13}$ Convenções utilizadas nos exemplos em (20) e (21): elemento em negrito $=$ tópico ou foco; $3^{\mathrm{a}}=$ terceira pessoa; cont.= contínuo; progr.cont.= progressivo contínuo.

${ }^{14}$ Oliveira, baseada em Rizzi (1997), ressalta que a presença de um elemento quantificacional seria um dos aspectos que diferem nas construções de foco e de tópico. No exemplo (21), o sintagma deslocado à esquerda wedenâi wa.hu.tsi, carrega um elemento quantificacional tsi (só/somente), o que provê uma outra evidência, além do fato de wedenâi wa.hu.tsi constituir informação nova, de que esse sintagma é de fato focalizado.

${ }^{15}$ O exemplo em (24) foi extraído de Oliveira (2002). Neste exemplo, "neg."= negação; "int"= interrogativa; "estat."= estativo.

${ }^{16}$ De acordo com Chomsky (1985), a Língua-E é definida como "a totalidade dos enunciados que podem ser produzidos numa comunidade de fala"; já a Língua-I é um objeto mental, o saber que as pessoas têm da língua e que lhes permite falar e entender essa língua.

17 O exemplo apresentado em Ex.l é extraído de Galves (1998) e o exemplo apresentado em Ex.2, de Raposo (1986).

${ }^{18}$ Exemplo extraído do corpus do projeto NURC.

${ }^{19}$ Conferir nota anterior.

${ }^{20}$ Exemplo extraído de Galves (1998).

${ }^{21}$ Gonçalves (1997) e Frota (2000) se baseiam nas definições de Nespor \& Vogel (1986) para sintagma fonológico e entoacional em PB e PE respectivamente. Conferir Nespor \& Vogel (1986) para os algoritmos de formação de sintagma fonológico e sintagma entoacional.

${ }^{22}$ Nos exemplos, os elementos em negrito são topicalizados e os exemplos em negrito e sublinhados são focalizados e portadores de proeminência fonológica principal da sentença. Quanto aos exemplos de foco e tópico extraídos de Gonçalves, acrescenta-se que o autor não apresenta o contexto que antecede o enunciado contendo tópico nem o contexto que antecede o enunciado contendo foco, por isso inserimos contextos possíveis antecedendo os enunciados apresentados em (25) e (26).

${ }^{23}$ Cabe acrescentar que é possível que o foco seja marcado pela sintaxe em PB, com o elemento focalizado ocupando a última posição na sentença, em contextos específicos de foco de apresentação (nos termos de Pilati, 2002; 2006), como em contexto de jogos (Ex.: Apitou o jogo o juiz.) - cf. Pilati, 2006 sobre esse tipo de foco em PB -, em casos de verbos inacusativos (exemplos: $O$ que que caiu? Caiu 
o botão ou O botão caiu; O que que chegou? A carta chegou ou Chegou a carta) cf. Kato \& Tarallo, 1998/2003; Tavares Silva, 2004; Fernandes, 2007; entre outros -, ou ainda, em casos de foco informacional com argumentos de verbos bitransitivos (exemplos: O que que você deu para o João? Eu dei para o João a bola; Pra quem você deu a bola? Eu dei a bola para o João.) - cf. Costa \& Figueiredo Silva, 2006. Quanto a este último caso, não há concordância consensual entre os falantes de PB sobre a preferência/aceitabilidade entre: (i) marcação do elemento focalizado através de proeminência principal da sentença assinalada a ele, independentemente da posição sintática que ocupa; e (ii) marcação do elemento focalizado essencialmente pela posição ocupada por ele na sentença (última posição). Assim, faz-se necessário ainda testar de maneira rigorosa (com base em análises empíricas embasadas estatisticamente) essas duas formas de expressão de focalização informacional dos argumentos de verbos bitransitivos em PB.

${ }^{24}$ Ainda quanto ao critério sintático, acrescenta-se que PB e PE também podem marcar foco pelo uso de estruturas clivadas, entretanto o estudo de tais estruturas nessas duas variedades se encontra fora do escopo deste trabalho. Sobre estruturas clivadas e a expressão da focalização, cf. Âmbar, 1997; 1999; Costa \& Duarte, 2000; Lobo, 2006 para o PE; Modesto, 2001 para o PB; e Fernandes, 2007 para PB e PE; entre outros.

\section{Referências Bibliográficas}

ÂMBAR, M. M. The syntax of focus in Portuguese - a unified approach. Lisboa: Universidade de Lisboa, ms., 1997.

. Aspects of the syntax of focus in Portuguese. In: REBUSCHI, G.; TULLER, L. (Ed.). The grammar offocus. Amsterdam/Philadelphia: John Benjamins, 1999.

AISSEN, J. L. Topic and focus in Mayan. Language 68(1), p. 43-80, 1992.

BENINCÁ, P. The position of topic and focus in the left periphery. In: CINQUE, G. ; SALVI, G. (Ed.). Current studies in Italian syntax. Amsterdam: Ed. Elsevies, 2001. p. 39-64.

BOLINGER, D. Accent is predictable (if you're a mind-reader). Language 48, p. 633-644, 1972.

BURGESS, E. Foco e tópico em xavante. Série Lingüística, p. 11-38, 1987.

CHAFE, W. Giveness, contrastiveness, definiteness, subjects, topics, and point of view. In: LI, C. N. (Ed.). Subject and topic. New York: Academic Press, 1976. 
CHOMSKY, N. Deep structure, surface structure and semantic interpretation. In: STEINBERG, D.; JAKOBOVITS, L. (Ed.). Semantics: an interdisciplinary reader in philosophy, linguistics and psychology. Cambridge, UK: Cambridge University Press, 1971. 1985.

Knowledge of language, Its nature origin and use. New York: Praeger,

CINQUE, G. A null theory of phrase and compound stress. LI 24, p. 239-97, 1993.

COSTA, J. Word order variation. A constaint-based approach. Netherlands: Holland Academic Graphics, 1998.

. Subject positions and interfaces: the case of European Portuguese. Berlin/ New York: Mouton de Gruyter, 2004.

; DUARTE, I. Minimizando a estrutura: uma análise unificada das construções de clivagem em português. In: XV Encontro Nacional da Associação Portuguesa de Linguística, 1, 2000. Actas. Coimbra: APL, 2000.

; FIGUEIREDO SILVA, M. C. On the (in)dependence relation between syntax and pragmatics. In: MOLNÁR, V.; WINKLER, S. (Org.). The Architecture of Focus. Berlin: Walter de Gruyter, 2006. p. 83-104.

CULICOVER, P. W.; ROCHEMONT, M. Stress and focus in English. Language 59, p. 123-165, 1983.

CRAIG, C. The structure of Jacaltec. Austin: University of Texas Press, 1977.

DE JONG, J. On the treatment of focus in functional grammar. GLOT, Leids Taalkundig Bulletin 3, p. 89-115, 1980.

DUARTE, F. B. Ordem de constituintes e movimento em tembé: minimalismo e anti-simetria. 2003. Tese (Doutorado em Lingüística) - Faculdade de Letras, Universidade Federal de Minas Gerais, Minas Gerais.

DUARTE, I. A construção de topicalização na gramática do português: regência, ligação e condições sobre movimento. 1987. Tese (Doutorado em Lingüística) FLUL, Universidade de Lisboa, Lisboa.

A topicalização em português europeu: uma análise comparativa. In: Congresso Internacional sobre o Português, 1, 1996. Actas. Lisboa: APL/Colibri, 1996. p. 327-360.

FERNANDES, F. R. Ordem, focalização e preenchimento em português: sintaxe e prosódia. 2007. Tese (Doutorado em Linguiística) - IEL, Universidade Estadual de Campinas, Campinas. 
FROTA, S. Prosody and focus in European Portuguese. Phonological phrasing and intonation. New York: Garland Publishing, 2000.

GALVES, C. A gramática do português brasileiro. Línguas e instrumentos lingüísticos 1, 1998.

GIVÓN, T. Syntax: a functional-typological introduction, v. II. Amsterdam/ Philadelphia: John Benjamins, 1990.

GONÇALVES, C. A. V. Focalização no português do Brasil. 1997. Tese (Doutorado em Lingüística) - Faculdade de Letras, Universidade Federal do Rio de Janeiro, Rio de Janeiro.

GUSSENHOVEN, C. Focus, mode and the nucleus. Journal of Linguistics 19, p. 377-417, 1983.

Sentence accents and argument structure. In: ROCA, I. (Ed.). Thematic Structure: its role in grammar. Berlin/New York: Foris, 1992. p. 79-106.

. Types of focus in English. In: LEE, C.; GORDON, M.; BÜRING, D. (Ed.). Topic and focus: cross-linguistic perspectives on meaning and intonation. Dordrecht: Kluwer, 2006.

HALE, K.; SELKIRK, E. Government and tonal phrasing in Papago. Phonology Yearbook 4, p. 151-184, 1987.

JACKENDOFF, R. Semantic interpretation in generative grammar. Cambridge: MIT Press, 1972.

KATO, M. A.; TARALLO, F. The loss of VS syntax in Brazilian Portuguese. In: SCHLIEBEN-LANGE, B.; VILLAÇA KOCH, I.; JUNGBLUTH, K. (Org.). Dialog zwischen den Schulen. Münster: Nodus Publikationen, 1988 [2003].p. 101-129.

KIDWAY, A. Word Order and Focus Positions in Universal Grammar. In: REBUSCHI, G.; TULLER, L. (Ed.). The grammar of focus. Amsterdam/Philadelphia: John Benjamins, 1999.

LADD, D. R. The structure of intonational meaning: evidence from English. Bloomington, Indiana: Indiana University Press, 1980. . Intonational phonology. Cambridge: CUP, 1996.

LI, C.; THOMPSON, S. Subject and topic: A new typology of language. In: LI, C. N. (Ed.). Subject and topic. New York: Academic Press, 1976.

LOBO, M. Assimetrias em construções de clivagem do português: movimento vs. geração na base. In: XXI Encontro Nacional da Associação Portuguesa de Lingüística, 2006. Actas - Textos seleccionados. Porto: APL, 2006. p. 457-473. 
MODESTO, M. As construções clivadas no português do Brasil: relações entre interpretação focal, movimento sintático e prosódia. São Paulo: Humanitas-FFLCH (USP), 2001.

NESPOR, M.; VOGEL, I. Prosodic phonology. Dordrecht: Foris Publications, 1986.

OLIVEIRA, R. C. Periferia esquerda na língua xavante. 2002. Dissertação (Mestrado em Lingüística) - Faculdade de Letras, Universidade Federal do Rio de Janeiro, Rio de Janeiro.

PILATI, E. N. S. Sobre a ordem verbo sujeito no português do Brasil. 2002. Dissertação (Mestrado em Lingüística) - Universidade de Brasília, Brasília.

Aspectos sintáticos e semânticos das orações com ordem verbo-sujeito no português do Brasil. 2006. Tese (Doutorado em Lingüística) - Universidade de Brasília, Brasília.

PONTES, E. O tópico no português do Brasil. Campinas: Pontes, 1987.

PUSKAS, G. Focus and the CP domain. In: HAEGEMAN, L. (Ed.). The new comparative syntax. London: Longman, 1997.

RAPOSO, E. On the null object in European Portuguese. In: JAEGGLI, O.; SILVACORVALAN, C. (Org.). Studies in Romance Linguistics. Dordrecht: Foris, 1986.

REINHART, T. Interface strategies. Utrecht: OTS Working Papers, 1995.

RIZZI, L. The Fine Structure of Left Periphery. In: HAEGEMAN, L. (Ed.). Elements of grammar. Kluwer Academic Publishers, 1997.

RODRIGUES, A. D. Macro-Jê. In: DIXON, R. M. Y.; ALEXANDRA, Y. (Ed.). The Amazonian languages. Aikhenvald, Cambridge: Cambridge University Press, 1999. p. 165-206.

ROSS, J. R. Constraints on Variables in Syntax. 1967. Tese (Doutorado em Lingüística) - M.I.T., Cambridge, Mass..

SCHMERLING, S. Aspects of English sentence stress. Austin: University of Texas Press, 1976.

TAVARES SILVA, C. R. A natureza de AGR e suas implicações na ordem VS: um estudo comparativo entre o português brasileiro e o português europeu. 2004. Tese (Doutorado em Lingüística) - Faculdade de Letras, Universidade Federal de Alagoas, Alagoas.

WINKLER, S. Focus and Secondary Predication. Berlin: Mouton, 1997.

ZUBIZARRETA, M. L. Prosody, Focus and Word Order. Cambridge, Mass: M. I. T. Press, 1998. 